\title{
Cardiac Hypertrophy and Altered Hemodynamic Adaptation in Growth-Restricted Preterm Infants
}

\author{
JAANA A. LEIPÄLÄ, TALVIKKI BOLDT, URSULA TURPEINEN, OLLI VUOLTEENAHO, AND \\ VINETA FELLMAN \\ Hospital for Children and Adolescents, University of Helsinki, Helsinki, Finland [J.A.L., T.B., V.F.]; \\ Laboratory, Helsinki University Central Hospital, Helsinki, Finland [U.T.]; Department of Physiology, \\ University of Oulu, Oulu, Finland [O.V.]
}

\begin{abstract}
The objective was to elucidate hemodynamic adaptation in very low birth weight $(<1500 \mathrm{~g})$ infants after intrauterine growth retardation. 31 growth-retarded (SGA, birth weight $<-2 \mathrm{SD}$ ) and 32 appropriate for gestational age (AGA, birth weight within \pm 1 SD range) infants were enrolled. In SGA infants, the diastolic diameters of the interventricular septum and the left ventricle were increased, and serum brain natriuretic peptide (BNP) was elevated. Left ventricular output (LVO) of the AGA infants increased from $150 \pm 28$ to $283 \pm 82 \mathrm{~mL} / \mathrm{kg} / \mathrm{min}$ during the study $(p<0.01)$. The SGA infants had a higher initial LVO than the AGA infants $(243 \pm 47$ versus $150 \pm 28 \mathrm{~mL} / \mathrm{kg} / \mathrm{min}, p<$ $0.05)$, but did not show further LVO increase during the study period. Red cell (RCV) and blood (BV) volume were assessed by $\mathrm{Hb}$ subtype analysis, when packed donor red cells were transfused. RCV and BV did not differ between the groups initially, but RCV increased by $18 \%$ and BV by $29 \%$ in the AGA group during the first $3 \mathrm{~d}$. On day 3 , AGA infants had larger BV than the SGA infants $(88 \pm 5$ versus $73 \pm 12 \mathrm{~mL} / \mathrm{kg}, p<0.05)$. In conclusion, cardiac hypertrophy, elevated initial LVO and BNP of the SGA infants suggest increased cardiac workload after
\end{abstract}

\section{ABSTRACT}

intrauterine growth retardation. Based on the $\mathrm{BV}$ and $\mathrm{RCV}$ data, blood volume regulation may also be impaired. The data suggest that SGA preterm infants may be exposed to an increased risk of circulatory failure during early adaptation. (Pediatr Res 53: 989-993, 2003)

$\quad$ Abbreviations
AGA, appropriate for gestational age
BNP, brain natriuretic peptide
BV, blood volume
LVEF, left ventricular ejection fraction
LVSF, left ventricular shortening fraction
HbA, adult Hb
HbF, fetal Hb
IVSD, diastolic inter ventricular thickness
LVEDD, end-diastolic diameter of the left ventricle
LVO, left ventricular output
RCV, red cell volume
SGA, small for gestational age
SV, stroke volume

Intrauterine growth retardation is associated with increased neonatal mortality, perinatal complications and long-term neurologic sequelae in preterm infants (1), as well as compromised cardiovascular adaptive capacity already in utero (2-4). However, few data have been reported regarding early circulatory adaptation after intrauterine growth retardation. In addition to myocardial performance, adequate intravascular volume is essential for successful postnatal cardiovascular adaptation. Largely due to the lack of applicable methodology, present knowledge on intravascular volume of preterm infants in gen-

Received June 24, 2002; accepted November 4, 2002.

Correspondence: Jaana A. Leipälä, 4th Floor, Frederic Still Ward, Golden Jubilee Wing, King's College Hospital, London SE5 9RS, United Kingdom; e-mail jaana.leipala@kcl.ac.uk

The study was supported by The Finnish Pediatric Research Foundation and The Medical Society of Finland (Finska Läkaresällskapet).

DOI: 10.1203/01.PDR.0000061564.86797.78 eral is scarce, and the effect of growth retardation on circulating volume has not been studied.

The aim of the present study was to test the hypothesis that fetal growth retardation alters the pattern of early hemodynamic adaptation of very low birth weight infants. During the first two weeks of life, left ventricular function and dimensions were assessed by echocardiography in SGA infants and AGA control infants. A circulating indicator of ventricular dysfunction, BNP, was also measured. RCV and BV were determined by a method based on dilution of autologous $\mathrm{HbF}$ by donor $\mathrm{HbA}$ when red cells were transfused based on clinical judgment. Hemodynamic evaluation was also performed by using indirect indices applied in routine clinical work.

\section{METHODS}

Patients. All infants in the study were born in the maternal unit of the Helsinki University Hospital and treated in the 
neonatal intensive care unit of the same hospital. Infants with a birth weight less than $1500 \mathrm{~g}$ and indwelling arterial lines were enrolled if the birth weight was less than -2 SD (SGA) or within $\pm 1 \mathrm{SD}$ range (AGA). Infants with acute birth asphyxia (umbilical artery $\mathrm{pH}$ less than 7.1), chromosomal abnormalities and major congenital heart disease were excluded from the study. Gestational ages were determined by fetal ultrasonography. The routine prenatal follow-up included fetal weight estimation by ultrasonographical assessment of abdominal circumference and early second-trimester fetal biparietal diameter measurement, determinations of umbilical blood flow, and cardiotocography applied for long-term fetal heart rate monitoring based on clinical judgment.

Monitoring. Systolic and mean arterial blood pressure, heart rate, and oxygen saturation were continuously monitored (Hewlett Packard Neonatal Component Monitoring System). Capillary refill time was recorded as described by Strozik et al. (5). The monitored values were recorded immediately before the echocardiography was performed.

Echocardiography and biochemical measurements. To obtain the circulating volume measurements simultaneously with the echocardiography, the patients were studied when packed donor red cells $(10 \mathrm{~mL}$ per $\mathrm{kg})$ were transfused based on clinical indication. The data from days 1,2 and 3 were analyzed separately, the data from days $4-6$ (mean 5) and day 7-14 (mean 10) were pooled. The study was repeated in the infants who received another transfusion with the arterial line still indwelling. LVO and stroke volume (SV) were measured before transfusion (all measurements performed by the same cardiologist) using an Acuson 128/XP10 scanner (7 MHz). The flow velocity integral of the maximal velocity in the ascending aorta (suprasternal view) was measured with continuous-wave Doppler. The internal diameter of aortic annulus was measured using frame-by-frame analysis of the 2-D image in the parasternal long axis view. LVO was calculated from the equation: $\mathrm{LVO}=$ cross sectional aortic area $\left(\mathrm{cm}^{2}\right)$ multiplied by flow velocity integral $(\mathrm{cm})$ multiplied by heart rate per minute. The presence of ductus arteriosus was defined using color Doppler. End-diastolic diameter of the left ventricle (LVEDD), diastolic inter ventricular thickness (IVSD), left ventricular shortening fraction (LVSF) and ejection fraction (LVEF) were measured by M-mode from parasternal long axis view of the ventricle at the junction of the mitral valve leaflets and papillary muscles.

BNP was measured by RIA after extraction of the samples with SepPak $\mathrm{C}_{18}$ cartridges as described previously (6). The sensitivity of the assay was $0.3 \mathrm{fmol} / \mathrm{tube}$. The within and between assay coefficients of variation were $<10$ and $<15 \%$, respectively. The assay does not cross-react with atrial or C-type natriuretic peptide $(<0.1 \%)$. With the method, the BNP level in the plasma of healthy adults was $3.8 \pm 3.4 \mathrm{pmol} / \mathrm{L}$. In healthy neonates, plasma BNP concentration is highest at $0 \mathrm{~d}$ of age (up to 30 times higher than the adult level) and decreases thereafter reaching the adult level at three months of age (7).

The volume assessment was performed by a modification of the $\mathrm{Hb}$ subtype method described by Phillips et al. (8). An arterial blood sample was drawn before transfusion (immediately after echocardiography), and $15 \mathrm{~min}$ after the transfusion.
$\mathrm{Hb}$ subtypes $\mathrm{HbF}$ and $\mathrm{HbA}$ were separated by liquid chromatography by using a PolyCAT A-cation exchange column (PolyLC Inc.), and determined by Applied Biosystems absorbance detector as previously described (9). RCV and BV were calculated based on the change in the relative amounts of $\mathrm{Hb}$ subtypes caused by the transfusion.

Statistics. The data were analyzed by one-way ANOVA, the two-tailed Student's $t$ test, the $\chi^{2}$ test and the Wilcoxon rank sum test. A $p$ value $<0.05$ was considered significant.

Ethical considerations. The study was approved by the hospital ethical committee and was conducted according to the principles of the Declaration of Helsinki. Informed written parental consent was obtained before enrollment.

\section{RESULTS}

Characteristics of the study population are shown in Table 1. Preeclampsia was the most common cause of growth retardation. There were no cases of maternal malnutrition in the study population. Cardiac diameters in relation to weight were increased after growth restriction (Fig. 1). Serum BNP correlated significantly with both IVSD (Pearson correlation 0.727, significant at the 0.01 level) and LVEDD (Pearson correlation 0.317 , significant at the 0.05 level). Serum BNP was $27 \pm 13$ $\mathrm{pmol} / \mathrm{L}$ in the AGA and $48 \pm 53 \mathrm{pmol} / \mathrm{L}$ in SGA infants $(p<$ $0.05)$.

Initially, LVO was larger in the SGA than the AGA infants (243 \pm 47 versus $150 \pm 28 \mathrm{~mL} / \mathrm{kg} / \mathrm{min}, p<0.05)$. A gradual increase of LVO was observed during the study period in the AGA infants (LVO was increased by $39 \%$ on day 3 and by $89 \%$ in the end of the study), whereas no LVO increase occurred in the SGA infants (Fig. 2). This difference was also observed in the infants studied repeatedly: in the 12 AGA infants studied twice LVO was $200 \pm 54 \mathrm{~mL} / \mathrm{kg} / \mathrm{min}$ in the first and $247 \pm 68 \mathrm{~mL} / \mathrm{kg} / \mathrm{min}$ in the second assessment $(p<0.05)$, whereas in the 15 SGA infants studied twice LVO remained similar $(224 \pm 105$ versus $246 \pm 57 \mathrm{~mL} / \mathrm{kg} / \mathrm{min}, \mathrm{NS})$. There was a close correlation of LVO to SV (Pearson correlation $0.927, p<0.01)$, but no significant correlation with mean arterial blood pressure and capillary refill time. Similarly to LVO, SV on day 1 was significantly greater in the SGA compared with the AGA infants $(1.51 \pm 0.32$ versus $0.95 \pm$ $0.17, p<0.05)$, and did not increase in the SGA infants thereafter. The indices of contractility did not differ between the groups: mean LVSF of all measurements was $36.5 \pm 6.2 \%$ in the AGA and $36.7 \pm 6.2 \%$ in the SGA infants, mean LVEF $70.4 \pm 7.9 \%$ and $70.8 \pm 8.6 \%$, respectively. At the time of the study mean heart rate was $158 \pm 15.8$ beats per minute in the

Table 1. Characteristics of the study groups

\begin{tabular}{lcc}
\hline & AGA $(n=32)$ & SGA $(n=31)$ \\
\hline Gestational age (weeks) & $27.2 \pm 1.8(24.0-30.9)$ & $28.4 \pm 2.4(23.3-32.4)$ \\
Birth weight $(\mathrm{g})$ & $1006 \pm 215(630-1485)$ & $810 \pm 242(405-1300)^{*}$ \\
Male/Female $(n)$ & $21 / 11$ & $22 / 9$ \\
Antenatal steroid $(n)$ & $28(88 \%)$ & $28(90 \%)$ \\
Pre-eclampsia $(n)$ & $4(13 \%)$ & $19(61 \%)^{*}$ \\
\hline
\end{tabular}

Values are mean $\pm \mathrm{SD}$.

$* p$ vs AGA $<0.01$. 


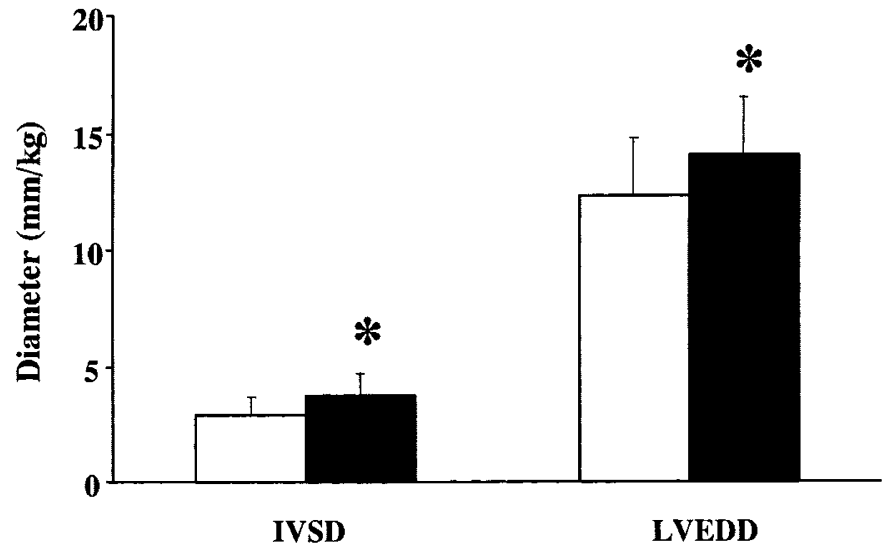

Figure 1. IVSD and LVEDD in relation to body weight ( $\mathrm{mm} / \mathrm{kg}$ ) of AGA (white columns) and SGA (black columns) preterm infants. * $p$ vs AGA $<0.05$. PDA was present in $28 \%$ of the AGA infants and $26 \%$ of the SGA infants during the study (NS difference).

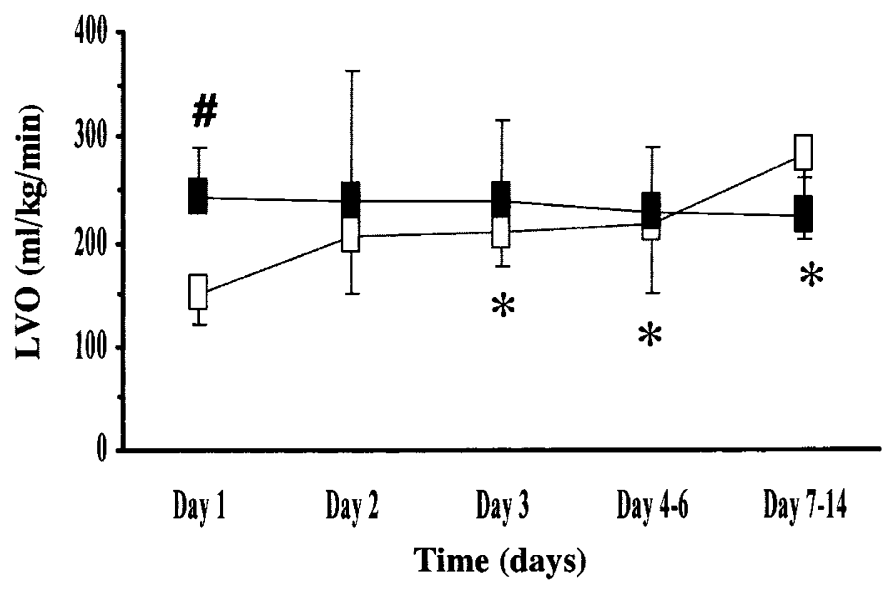

Figure 2. LVO (ml $/ \mathrm{kg} / \mathrm{min}$ ) of AGA (white symbols) and SGA (black symbols) preterm infants. ${ }^{*} p$ vs day $1<0.05, \# p$ vs AGA $<0.05$.

AGA infants, and $158 \pm 16.4$ in the SGA infants. No significant differences were observed when data from the different study times were analyzed separately. 13 AGA infants and 18 SGA infants were treated with catecholamines (NS difference).

$\mathrm{RCV}$ and $\mathrm{BV}$ did not differ between the groups initially, but both volumes increased in the AGA infants during the first $3 \mathrm{~d}$ of life, and were significantly higher on day 3 than on day 1 (Table 2). Compared with day $1, \mathrm{RCV}$ and $\mathrm{BV}$ remained unaltered till the end of the first week in the SGA group. RCV correlated with hematocrit (Pearson correlation 0.569, $p<$ 0.01 ) but not with LVO, systolic blood pressure, mean arterial blood pressure, heart rate and capillary refill time. BV correlated significantly only to RCV (Pearson correlation 0.892, $p<$ 0.01 ). There were no significant differences in the indirect indices of hemodynamics between the AGA and SGA infants.

\section{DISCUSSION}

Echocardiographic studies have shown a redistribution of circulation diverting oxygenated blood from other tissues to sustain the growth of the brain, as well as a shift of cardiac flow in favor of the left side of the heart in growth-retarded fetuses $(10-12)$, but the immediate postnatal cardiovascular consequences of growth restriction have not been elucidated. The present study shows that fetal growth restriction is associated with alterations in early hemodynamic adaptation in low birth weight infants. Increased ventricular output and cardiac hypertrophy occur in fetal animals in chronic anemia and hypoxia $(13,14)$, and increased LVO and decreased ratio of right to left ventricular output has been reported in growth-retarded human fetuses (12). This redistribution of the ventricular outputs can be understood in the light of the fact that the output of the fetal left ventricle is directed mainly to the brain, whereas the output of the right ventricle is directed to the lower body and placenta. A redistribution of cardiac output in favor of the left heart is therefore in accordance with the brain-sparing effect in intrauterine growth retardation, and most likely due to selective changes in peripheral vascular resistance (15). The septal and left ventricular hypertrophy observed in SGA infants in the present study could be explained by increased left ventricular work load in utero resulting from a shift in the left-to-right output ratio. Another possible explanation for an increased left ventricular afterload is impaired systemic vascular resistance. Low birth weight has been reported to be linked to decreased endothelium-dependent vascular dilatation later in life $(16,17)$. Furthermore, it has recently been suggested that this association is more likely due to growth restriction than to a low birth per se (18). We did not find any significant differences in LVEF and LVSF between the AGA and SGA infants, the mean values for these indices being well in the normal range $(=27 \%$ or more for LVSF, $55 \%$ or more for LVEF) in both groups. Thus the altered LVO after intrauterine growth retardation is more likely explained by changes of vascular resistance than contractility.

Increased cardiac output has been observed in SGA infants on day 1 also by Martinussen et al. (19). The higher initial LVO in the SGA infants could also be due to compensation of fetal tissue hypoxia. Although augmented LVO may counter-

Table 2. $R C V$ and $B V$ of $A G A$ and SGA preterm infants receiving red cell transfusions measured with hemoglobin subtype analysis

\begin{tabular}{|c|c|c|c|c|}
\hline & \multicolumn{2}{|c|}{$\mathrm{RCV}(\mathrm{ml} / \mathrm{kg})$} & \multicolumn{2}{|c|}{$\mathrm{BV}(\mathrm{ml} / \mathrm{kg})$} \\
\hline & AGA & SGA & AGA & SGA \\
\hline Day 1 & $30.0 \pm 1.8(5)$ & $32.6 \pm 8.1(6)$ & $67.9 \pm 7.7(5)$ & $67.6 \pm 13.1(6)$ \\
\hline Day 3 & $35.3 \pm 3.3(5)^{*}$ & $34.2 \pm 8.9(6)$ & $87.9 \pm 5.2(5)^{*}$ & $72.6 \pm 12.0(6) \dagger$ \\
\hline Day 4-6 & $28.4 \pm 5.0(11)$ & $31.8 \pm 7.4(12)$ & $64.5 \pm 9.9(11)$ & $72.5 \pm 9.4(12)$ \\
\hline Day 7-14 & $23.4 \pm 4.5(5)^{*}$ & $23.7 \pm 7.7(8)$ & $63.0 \pm 10.7(5)$ & $58.2 \pm 15.5(8)$ \\
\hline
\end{tabular}

Values are mean $\pm \mathrm{SD}, n$ in parentheses.

$* p$ vs day $1<0.05, \dagger p$ vs $\mathrm{AGA}<0.05$. 
balance for some sequelae of growth retardation, SGA infants may have limited capacity for further cardiac adaptation, since they are unable to increase their LVO postnatally, in contrast to the AGA infants. Interestingly, elevated cardiac output has been observed in a prospective study in pregnant women already before the clinical diagnosis of preeclampsia (20), and a high cardiac output has been proposed to act as a compensatory mechanism for decreased uteroplacental circulation (21). Our data suggest that similar mechanisms of cardiac compensation may be activated in the fetuses and the mothers in pregnancies complicated by preeclampsia. Since there was no initial difference in the intravascular volume between the groups, it is not likely that the LVO increase was due to an increased preload. Respiratory distress syndrome and persistent ductus arteriosus influence LVO of preterm infants (22), but the altered pattern of LVO development observed in the present study cannot be explained by differences in respiratory or ductal factors, nor by differences in vasopressor treatment, since these did not differ significantly between the groups at the studied points of time.

Cardiac hypertrophy observed in the SGA infants is in accordance with the previously reported hypertrophy of both ventricles in growth-retarded fetuses $(3,4)$. The most probable mechanism of this hypertrophy is prolonged exposure to an increased myocardial workload, which could also account for the elevated BNP in the SGA infants observed in the present study. Circulating BNP levels are known to correlate with ventricular dysfunction, left ventricular wall thickness and left ventricular mass (e.g. refs. 23, 24). Together the present observations, altered postnatal pattern of LVO, cardiac hypertrophy and increased BNP suggest that SGA infants are exposed to a significant cardiovascular stress in utero. They may thus be more susceptible to circulatory failure than AGA infants. Accumulating recent evidence has linked fetal growth retardation to cardiovascular diseases in adult life (Barker's hypothesis, ref. 25). Therefore it is tempting to speculate that the hemodynamic changes observed in the present study may be permanent. Further study is needed to establish whether this is the case.

Intravascular volume in relation to intrauterine growth has been previously studied only in polycythemic infants receiving a partial plasma exchange transfusion, in whom circulating volume was larger in SGA than AGA infants, but most of the SGA infants included in the study were full-term (26). Brans et al. (27) observed no alterations after intrauterine growth deviations in the plasma and blood volumes in appropriately grown, growth-retarded and macrosomic full or near-term polycythemic infants studied within $32 \mathrm{~h}$ of birth. The $\mathrm{Hb}$ subtype method allows RCV and BV assessment in any newborn requiring a red cell transfusion (8). Analogously to their postnatal profile of LVO, the SGA infants failed to increase their blood volume during the first days of life. This suggests that intravascular volume regulation may also be impaired by fetal growth restriction.

In contrast to the echocardiographic and biochemical assessment, conventional indirect indices of hemodynamics (blood pressure, heart rate and capillary refill time) did not reveal any differences between the study groups. This emphasizes that a subclinical but potentially significant cardiovascular compromise cannot be detected simply by monitoring these parameters. Of the techniques applied in the present study, echocardiographic measurement of cardiac output is the most practical addition to the clinical setting. The usefulness of the $\mathrm{Hb}$ subtype method for BV estimation in routine care is limited by two factors: it can only be performed when a red cell transfusion is given, and the time needed for sample preparation and separation of the $\mathrm{Hb}$ subtypes is too long for most clinical purposes.

\section{CONCLUSION}

In conclusion, intrauterine growth retardation is associated with alterations of cardiovascular adaptation as well as septal and left ventricular hypertrophy in newborn low birth weight infants. Although the data indicate that SGA fetuses are capable of considerable cardiovascular compensation, they may still be exposed to an increased risk of circulatory failure later. It still remains to be established whether the hemodynamic changes observed in SGA newborns are permanent.

Acknowledgments. We thank Dr. Marjo Talme for assistance in the red cell and blood volume measurements.

\section{REFERENCES}

1. Leipälä J, Greenough A 2002 The short and long term effects of intrauterine growth retardation. Contemp Clin Gynecol Obstet 2:161-167

2. Räsänen J, Kirkinen P, Jouppila P 1989 Right ventricular dysfunction in human fetal compromise. Am J Obstet Gynecol 161:136-140

3. Veille JC, Hanson R, Sivakoff M, Hoen H, Ben-Ami M 1993 Fetal cardiac size in normal, intrauterine growth retarded, and diabetic pregnancies. Am J Perinatol 10:275-279

4. Murotsuki J, Challis JRG, Han VKM, Fraher LJ, Gagnon R 1997 Chronic fetal placental embolization and hypoxemia cause hypertension and myocardial hypertrophy in fetal sheep. Am J Physiol 272:R201-R207

5. Strozik KS, Pieper CH, Cools F 1998 Capillary refilling time in newborns - optimal pressing time, sites of testing and normal values. Acta Paediatr 87:310-312

6. Vuolteenaho O, Koistinen P, Martikkala V, Takala T, Leppäluoto J 1992 Effect of physical exercise in hypobaric conditions on atrial natriuretic peptide secretion. Am J Physiol 263:R647-R652

7. Yoshibayashi M, Kamiya T, Saito Y, Nakao K, Nishioka K, Temma S, Itoh H, Shirakami G, Matsuo H 1995 Plasma brain natriuretic peptide concentrations in healthy children from birth to adolescence: marked and rapid increase after birth. Eur J Endocrinol 133:207-209

8. Phillips HM, Holland BM, Abdel-Moiz A, Fayed S, Jones JG, Turner TL, Wardrop CA, Cockburn F 1986 Determination of red-cell mass in assessment and management of anaemia in babies needing blood transfusion. Lancet 19:1:882-884

9. Turpeinen U, Karjalainen U, Stenman U-H 1995 Three assays for glycohemoglobin compared. Clin Chem 41:191-195

10. Rizzo G, Arduini D, Romanini C, Mancuso S 1988 Doppler echocardiographic assessment of atrioventricular velocity waveforms in normal and small for gestational age fetuses. Br J Obstet Gynaecol 95:65-69

11. Al-Ghazali W, Chita SK, Chapman MG, Allan LD 1989 Evidence of redistribution of cardiac output in asymmetrical growth retardation. Br J Obstet Gynaecol 96:697-704

12. Rizzo G, Arduini D 1991 Fetal cardiac function in intrauterine growth retardation. Am J Obstet Gynecol 165:876-882

13. Reller MD, Morton MJ, Giraud GD, Wu DE, Thornburg KL 1992 Severe right ventricular pressure loading in fetal sheep augments global myocardial blood flow to submaximal levels. Circulation 86:581-588

14. Martin C, Yu AY, Jiang BH, Davis L, Kimberly D, Hohimer AR, Semenza GL 1998 Cardiac hypertrophy in chronically anemic fetal sheep: Increased vascularization is associated with increased myocardial expression of vascular endothelial growth factor and hypoxia-inducible factor 1. Am J Obstet Gynecol 178:527-534

15. Wladimiroff JW, Wijngaard JAGW, Degani S, Noordam J, van Eyck J, Tonge HM 1987 Cerebral and umbilical arterial flow velocity waveforms in normal and growthretarded pregnancies. Obstet Gynecol 69:705-709

16. Leeson CP, Kattenhorn M, Morley R, Lucas A, Deanfield JE 2001 Impact of low birth weight and cardiovascular risk factors on endothelial function in early adult life. Circulation 6:103:1264-1268 
17. Martin H, Hu J, Gennser G, Norman M 2000 Impaired endothelial function and increased carotid stiffness in 9-year-old children with low birthweight. Circulation 28:102:2739-2744

18. Singhal A, Kattenhorn M, Cole TJ, Deanfield J, Lucas A 2001 Preterm birth, vascular function, and risk factors for atherosclerosis. Lancet 6:358:1159-1160

19. Martinussen M, Brubakk AM, Vik T, Yao AC 1997 Relationship between intrauterine growth retardation and early postnatal superior mesenteric artery blood flow velocity. Biol Neonate 71:22-30

20. Bosio PM, McKenna PJ, Conroy R, O’Herlihy C 1999 Maternal central hemodynamics in hypertensive disorders of pregnancy. Obstet Gynecol 94:978-984

21. Yang JM, Yang YC, Wang KG 1996 Central and peripheral hemodynamics in severe preeclampsia. Acta Obstet Gynecol Scand 75:120-126

22. Evans N, Kluckow M 1996 Early determinants of right and left ventricular output in ventilated preterm infants. Arch Dis Child 74:F88-F94
23. Hirata Y, Matsumoto A, Aoyagi T, Yamaoki K, Komuro I, Suzuki T, Ashida T, Sugiyama T, Hada Y, Kuwajima I, Nishinaga M, Akioka H, Nakajima O, Nagai R, Yazaki Y 2001 Measurement of plasma brain natriuretic peptide level as a guide for cardiac overload. Cardiovasc Res 51:585-91

24. McDonagh TA, Cunningham AD, Morrison CE, McMurray JJ, Ford I, Morton JJ, Dargie HJ 2001 Left ventricular dysfunction, natriuretic peptides, and mortality in an urban population. Heart $86: 21-26$

25. Barker DJP 1998 In utero programming of chronic disease. Clin Sci 95:115-128

26. Maetzdorf WJ, Aldenhuyzen-Dorland W, Slaaf DW, Tangelder GJ, Blanco CE 1991 Circulating blood volume in appropriate and small for gestational age full term and preterm polycythaemic infants. Acta Paediatr Scand 80:620-627

27. Brans YW, Shannon DL, Ramamurthy RS 1981 Neonatal polycythemia: II. Plasma, blood and red cell volume: estimates in relation to hematocrit levels and quality of intrauterine growth. Pediatrics 68:175-182 